Advocacy groups and the economic value of medical research

Your discussion on the economic impact of science (Nature 465, 682-684; 2010) is unjustifiably critical of advocacy groups.

For example, the US advocacy group Research!America presents an annual award that recognizes outstanding work by new economists who demonstrate the impact of medical research on the economy. This award, the Garfield Economic Impact Award, was established by Eugene Garfield, founder of the Institute for Scientific Information (now Thomson Reuters) and creator of the Science Citation Index. Garfield awardees are increasingly sought as sources and advisers by the White House, other elected officials and the media.

David Meltzer of the University of Chicago received the first Garfield Award in 2002 for developing mathematical tools to investigate whether a research plan is justified on economic grounds. He showed how to prioritize research projects and identify when further spending could be worthwhile.

The 2003 recipient, David Cutler of Harvard University, evaluated research into cardiovascular disease for the production of new therapies and information to guide patients' behaviour. He estimated the return to the economy from medical treatments to be about US\$4 for every $\$ 1$ spent, and from behavioural changes to be about $\$ 30$ for every $\$ 1$. He also found that there is a $\$ 7$ economic return for every $\$ 1$ spent on technological innovations in heart-attack care.

Although I hope that economists will corroborate the view that the economic impact of research is important, our commitment is to obtaining accurate economic information, so that policy-makers, researchers, businesses, advocates and the public will have a stronger basis for decision-making.

Mary Woolley Research!America, Alexandria, Virginia 22314, USA e-mail: mwoolley@researchamerica.org Competing financial interests: declared (see http://dx.doi. org/10.1038/466028a for details).

\section{Develop instruments to monitor volcanic ash fallout}

Air-traffic response to future incidents akin to the volcanic eruption in Iceland will be more effective if an automated instrument can be developed for continuous, near real-time monitoring of ash fallout from eruption plumes.

Ash from the Eyjafjallajökull eruption was carried towards Europe by prevailing winds. The height of the plume was used as the main indicator of mass transfer, a crucial input parameter in atmospheric models to define no-fly zones.

Although wind patterns are well understood, confusion over the ash load in volcanic plumes causes uncertainties in setting no-fly zone boundaries. The grain size and mass of ash fall per area can be used to reconstruct volcanic plumes. But this data would be more useful if operational in near real time.

Gravimetric measurements of the fallout weight could be used, for example, and a laserdispersion instrument might measure particle concentration and size in the air. For prolonged explosive eruptions such as the recent Icelandic one, an array of these instruments could be located under plume trails.

These observations would provide timely 'ground-truth' to calibrate and complement remote-sensing techniques that rely on radar, lidar (light detection and ranging) and satellite data.

Governments, airlines and aviation authorities should help to develop and test such instruments.

Freysteinn Sigmundsson, Ármann

Höskuldsson Nordic Volcanological Centre, University of Iceland, IS-101 Reykjavik, Iceland

e-mail: fs@hi.is

\section{Sino-European research ethics on the right path}

Guidelines are now in place to drive the ethical governance of biomedical research collaborations between Europe and China (www.bionet-china.org). Along with 30 intensively discussed recommendations, the key proposal by BIONET is to establish a standing Sino-European platform for research ethics.

BIONET's report is the culmination of a three-year project between 21 partners, funded by the European Commission's Sixth Framework Programme and the UK Medical Research Council, with support from the Chinese government. It covers research on clinical trials, biological banking and personal genomics, stem-cell research, and reproductive and regenerative medicine.

Important scientific collaborations have so far included multicentre clinical trials for European pharmaceutical companies by local contractors in China, where the economic, social and political conditions are more favourable, and the worldwide contribution of Chinese genomesequencing centres.

Many interdisciplinary ethicsreview boards have already been set up in China, and in 2000, the Ministry of Health established a National Ethics Committee. However, regulatory gaps remain: for example, socio-cultural differences in Europe and China have prompted concerns about how best to adapt the idea of informed consent within an ethical framework.

Christoph Rehmann-Sutter Universität zu Lübeck Königsstraße 42, 23552 Lübeck, Germany e-mail: rehmann@imgwf.uni-luebeck.de

\section{Gender agenda: sex bias can be justified in animal research}

Concern over gender bias in human clinical medicine is a separate issue from male bias in animal research (Nature 465, 665 and 688-690; 2010).

Justifications for using a particular sex in animal studies include intrinsic biological variation (for example, male aggressiveness, female hormonal cycling, disproportionate disease effect on one sex in some disease models) and practical considerations (such as preference for less-aggressive females that can be grouphoused to save money). Singlesex animal experiments will continue as long as research budgets are limited.

Best-practice standards for regulatory agencies and industry already require that both sexes be investigated in animal studies used for translational medicine, drug development and pesticide registration (see go.nature.com/ PA4U93). Although these animal data are indispensable for risk assessment for humans, they cannot reliably predict genderspecific responses in humans because of the physiological differences between species. Human data are needed before regulatory changes can be made to improve gender balance in human clinical trials.

To improve the quality and utility of animal-research data, any new mandate from journals and funding bodies on the conduct and reporting of animal studies should insist on full experimental details. In addition to gender balance, these would include key information for study interpretation, such as the animals' source, age, strain or stock, husbandry conditions and health status.

Brad Bolon GEMpath, 2867 Humboldt Circle, Colorado 80503-2339, USA e-mail:brad@gempath.net A full list of signatories is available at http://dx.doi.org/10.1038/466028d 